\title{
A case of retrograde intussusception at Roux-en-Y anastomosis 10 years after total gastrectomy: review of the literature
}

\author{
Yuhei Kitasato $^{1^{*}} \mathbb{D}$, Ryuta Midorikawa', Yoshihiro Uchino', Shuko Saku', Taizan Minami', Takahisa Shirahama', \\ Kazumitsu Kiyomatsu', Koji Okuda², Yoshito Akagi ${ }^{2}$ and Hiroyuki Tanaka²
}

\begin{abstract}
A 63-year-old man, who had undergone total gastrectomy and Roux-en-Y reconstruction for gastric cancer 10 years previously, was admitted to our hospital with complaints of abdominal pain, palpable abdominal tumor, and hematemesis. On admission, the abdominal tenderness was improving and no abdominal tumor was palpable. Mild inflammatory changes and anemia were noted on blood examination. Abdominal computed tomography revealed a tumor with a layered structure in the left abdomen. The patient was diagnosed with intestinal obstruction secondary to intussusception, and surgery was performed. Retrograde intussusception was found at the site of the $Y$ anastomosis. We conducted manual reduction using the Hutchinson procedure. The intestinal color after the reduction was good, and no intestinal resection was required. Postoperative recovery was uneventful, and the patient was discharged 12 days after surgery. Reports of jejunal intussusception after total gastrectomy with Roux-en-Y reconstruction are relatively rare. Here, we report a case of jejunal intussusception after total gastrectomy with Roux-en-Y reconstruction.
\end{abstract}

Keywords: Total gastrectomy, Retrograde intussusception, Roux-en-Y anastomosis

\section{Background}

Intussusception occurs when a portion of intestine invaginates into an adjacent section of intestine. Common physical exam findings in adults with intussusception include intermittent abdominal pain, vomiting, gastrointestinal bleeding, and/or the presence of a palpable mass. Possible sequelae of intussusception include small bowel obstruction and ischemia. Jejunal intussusception is a rare complication after gastrectomy and extremely rare after total gastrectomy. In this case study, we report a case of retrograde intussusception at Roux-en-Y anastomosis occurring 10 years after total gastrectomy. We also review other cases of intussusception after total gastrectomy that are reported in the literature.

\section{Case presentation}

A 63-year-old man, who had undergone total gastrectomy and Roux-en-Y reconstruction for early gastric cancer 10 years previously, was transferred to our institution from

\footnotetext{
* Correspondence: kitasato_yuuhei@kurume-u.ac.jp

'Department of Surgery, JCHO Saga Central Hospital, 3-8-1 Hyogo-minami,

Saga, Saga 849-8522, Japan

Full list of author information is available at the end of the article
}

a local hospital with complaints of intermittent abdominal pain, palpable abdominal tumor, and hematemesis. On arrival, he was hemodynamically stable, the abdominal tenderness was improving, and the abdominal tumor was not felt on physical examination. Mild inflammatory reaction and anemia were noted on blood examination. All other laboratory values were unremarkable and there was no evidence of acidosis.

Abdominal computed tomography (CT) revealed a tumor with a layered structure in the left abdomen (Fig. 1). Endoscopy revealed a bulky, rounded, congested mass that occupied the lumen beyond the esophagojejunal anastomosis (Fig. 2) and showed a small amount of oozing from the mucosal surface caused by disruption to the blood flow resulting from intussusception. These findings led to the diagnosis of intestinal obstruction caused by jejunal intussusception. Although we observed retrograde jejunal intussusception, endoscopic reduction was not attempted and surgical repair was performed by laparotomy.

Surgery revealed retrograde jejunal intussusception in the elevated jejunum through the $\mathrm{Y}$ anastomosis (Fig. 3a). We reduced the intussusception using the Hutchinson 


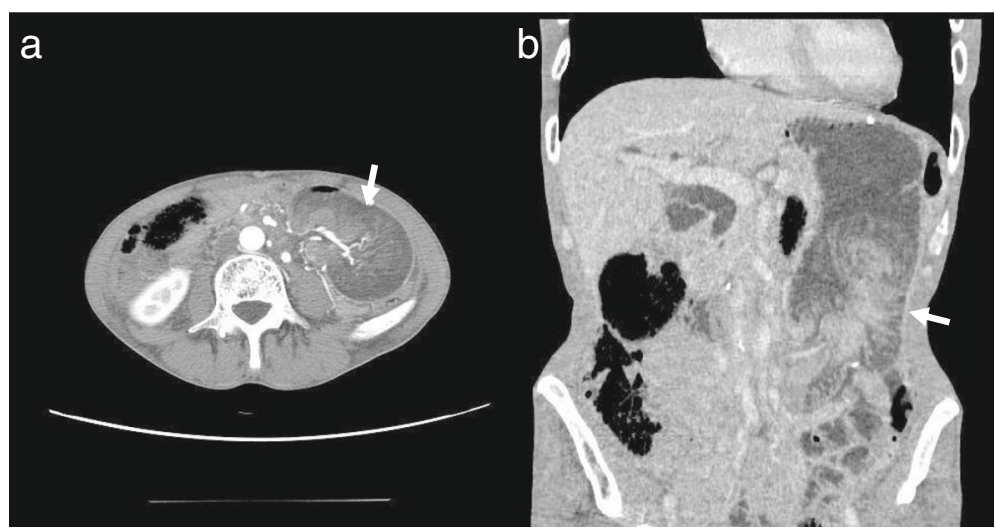

Fig. 1 a, b Abdominal computed tomography showing a tumor with a layered structure in the left abdomen (white arrow). Intestinal obstruction secondary to intussusception was suspected

procedure. The involved bowel was dilated, edematous, and congested, but there was no evidence of ischemia (Fig. 3b), and therefore, we performed only manual reduction and adhesiotomy without intestinal resection. The patient's postoperative recovery was free of complications, and he was discharged 12 days postoperatively. He has been alive without symptoms of bowel obstruction for 2 years after operation.

\section{Discussion}

Jejunal intussusception after gastrectomy was first reported by Bozzi [1] and is recognized as an uncommon complication, occurring in only $0.07-2.1 \%$ of patients who undergo gastrectomy [2]. Intussusception is attributed to both mechanical factors (excessive length

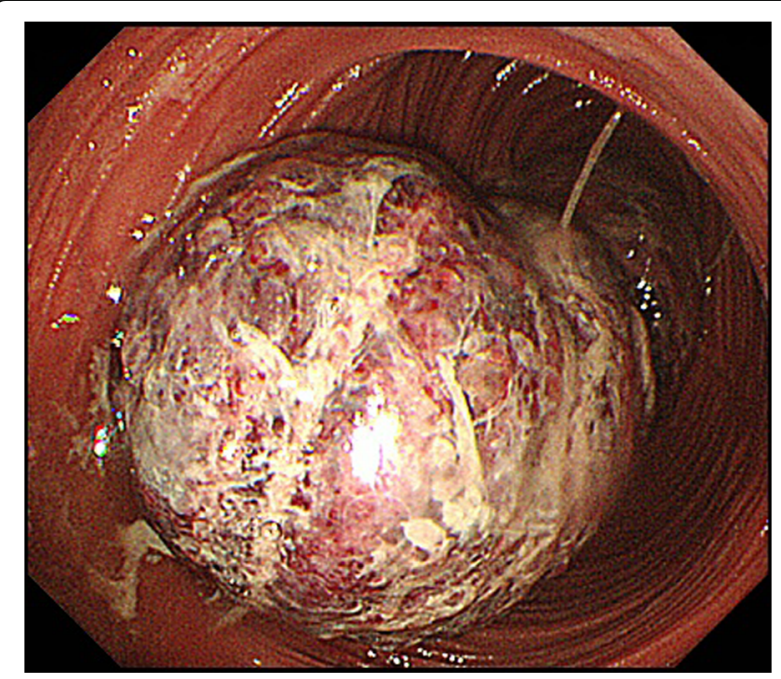

Fig. 2 Upper gastrointestinal endoscopy revealed congested mucosa of the small intestinal intussusception of afferent loop, lifting afferent loop to the stomach wall, excessively large anastomosis hole, ptosis of the gastrojejunal anastomosis, postoperative adhesions, and stenosis causing reverse peristalsis) and functional factors (spasm of the intestine, peristaltic abnormality, surgical stimulation, inflammation, autonomic nervous system abnormality, enteral nutrition, drug infusion, and decrease in gastric wall tension) $[2,3]$. At the site of the Roux-en-Y anastomosis in this case, adhesions were mild and no strictures or mass were observed that would cause reverse peristalsis. However, mechanical factors cannot be entirely ruled out in this patient; we suspect that some kind of peristaltic abnormality may have occurred. Tu and Kelly reported reverse peristalsis caused by an apparent ectopic pacemaker in a Roux-en-Y anastomosis of small intestinal resection [4]. This clinical condition may also cause retrograde intussusception after total gastrectomy and Roux-en-Y reconstruction.

Jejunal intussusception after total gastrectomy is rare. A review of the literature revealed 18 cases of intussusception occurring after total gastrectomy with Roux-en-Y reconstruction, including the current case (Table 1) [3, 5-18]. The majority of patients experiencing this complication were 60-70 years old. Only four cases of antegrade intussusception were observed; the other cases were retrograde intussusception. Furthermore, only six cases developed in the early postoperative period; other cases developed 1-22 years after surgery.

In 12 of the 18 reported cases, enterectomy was not performed. Kita et al. reported recurrence of intussusception within 1 year of manual reduction of intussusception. Recurrence may be more likely when only manual reduction is used, and therefore, resection and re-anastomosis should be considered [18]. We think that we may prevent retrograde intussusception by making $\mathrm{Y}$ leg side-to-side anastomosis in the case of gastrectomy. 


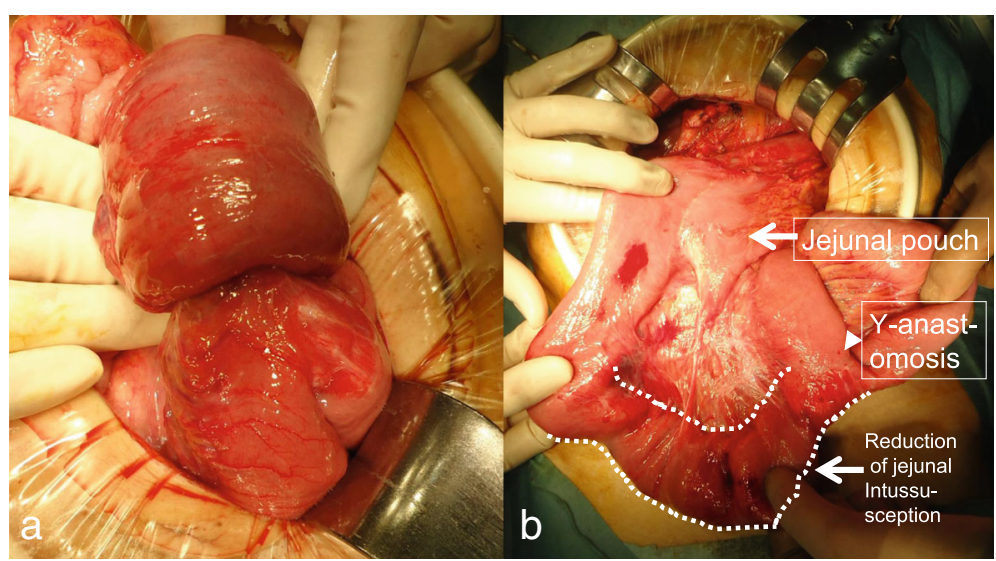

Fig. $\mathbf{3}$ a, b Intraoperatively, a retrograde intussusception at the $Y$-anastomosis was observed (a). Manual reduction was performed using the Hutchinson procedure (b). The color of intussuscepted intestine after the reduction was good, and intestinal resection was unnecessary (black arrow: jejunal pouch, white arrowhead: Y-anastomosis, surrounded by the dotted line and white arrow: intussuscepted intestine)

Table 1 Cases of jejunal intussusception after total gastrectomy with Roux-en-Y reconstruction

\begin{tabular}{|c|c|c|c|c|c|c|c|c|}
\hline Case & Age & Sex & Diagnosis & $\begin{array}{l}\text { Time after } \\
\text { gastrectomy }\end{array}$ & $\begin{array}{l}\text { Type of } \\
\text { intussusception }\end{array}$ & Treatment & Year of reported & Author \\
\hline$\overline{1}$ & 63 & $M$ & Gastric cancer & 3 years & Retrograde & None & 1954 & Davey [3] \\
\hline 2 & 48 & $\mathrm{~F}$ & Gastric cancer & 23 days & Retrograde & $\begin{array}{l}\text { Partial resection of } \\
\text { jejunum }\end{array}$ & 1965 & Nishi \\
\hline 3 & 65 & M & Gastric cancer & 6 days & Retrograde & Manual reduction & 1965 & Kato et al. [5] \\
\hline 4 & 40 & M & Sarcoma & 5 years & Retrograde & $\begin{array}{l}\text { Partial resection of } \\
\text { jejunum }\end{array}$ & 1966 & Freeman et al.[6] \\
\hline 5 & 39 & $\mathrm{~F}$ & Gastric cancer & 16 days & Antegrade & Manual reduction & 1984 & Hanyu et al. [7] \\
\hline 6 & 61 & $\mathrm{~F}$ & Gastric cancer & 12 years & Retrograde & Manual reduction & 1993 & Hashimoto et al. [8] \\
\hline 7 & 58 & $\mathrm{~F}$ & Gastric cancer & 1 year & Retrograde & $\begin{array}{l}\text { Partial resection of } \\
\text { jejunum }\end{array}$ & 1994 & Narushima et al. [9] \\
\hline 8 & 75 & M & Esophageal cancer & 9 years & Retrograde & Manual reduction & 2000 & Goto et al. [10] \\
\hline 9 & 50 & $\mathrm{~F}$ & Gastric cancer & 10 days & Antegrade & Manual reduction & 2001 & Ozdogan et al. [11] \\
\hline 10 & 60 & M & Gastric cancer & 4 years & Retrograde & Manual reduction & 2005 & Akiyama et al. [12] \\
\hline 11 & 74 & M & Gastric cancer & 12 years & Retrograde & $\begin{array}{l}\text { Partial resection of } \\
\text { jejunum }\end{array}$ & 2005 & Matsumoto et al. [13] \\
\hline 12 & 74 & M & Gastric cancer & 21 years & Retrograde & Manual reduction & 2006 & Sato et al. [14] \\
\hline 13 & 75 & M & Gastric cancer & 10 years & Antegrade & Manual reduction & 2010 & Ueno et al. [15] \\
\hline 14 & 69 & M & Gastric cancer & 45 days & Antegrade & Manual reduction & 2012 & Matsuda et al. [16] \\
\hline 15 & 77 & $\mathrm{~F}$ & Gastric cancer & 5 days & Retrograde & Manual reduction & 2013 & Lee et al. [17] \\
\hline 16 & 75 & M & Gastric cancer & 21 years & Retrograde & Manual reduction & 2013 & Kita et al. [18] \\
\hline 17 & 76 & M & Gastric cancer & 22 years & Retrograde & $\begin{array}{l}\text { Partial resection of } \\
\text { jejunum }\end{array}$ & 2013 & Kita et al. [18] \\
\hline 18 & 63 & M & Gastric cancer & 10 years & Retrograde & Manual reduction & 2015 & Our case \\
\hline
\end{tabular}


This is because it thinks that it may do intussusception by the peristalsis that was handed down to intestinal tract by making end-to-side anastomosis.

\section{Conclusions}

We report a case of retrograde intussusception at Roux-en-Y anastomosis 10 years after total gastrectomy.

\section{Abbreviations}

$\mathrm{CT}$ : Computed tomography

\section{Acknowledgements}

We thank the entire staff of JCHO Saga Central Hospital for treating and caring for this patient.

\section{Funding}

No funding was received for this study.

\section{Authors' contributions}

YK, RM, TM, and KK performed the operation. YK wrote the manuscript. KK, $K O, Y A$, and $H T$ helped to write the manuscript and supervised the study. YK, $\mathrm{RM}, \mathrm{TM}, \mathrm{SS}, \mathrm{TS}, \mathrm{HU}$, and KK provided daily medical treatment for the patient. All authors read and approved the final manuscript.

\section{Competing interests}

The authors declare that they have no competing interests.

\section{Consent for publication}

Informed consent was obtained from the patient for publication of this case report and any accompanying images.

\section{Ethics approval and consent to participate}

We excluded all identifying information and obtained informed consent to participate. Because this is a case report, the approval of the ethical review board of our hospital is unnecessary.

\section{Author details}

'Department of Surgery, JCHO Saga Central Hospital, 3-8-1 Hyogo-minami, Saga, Saga 849-8522, Japan. ${ }^{2}$ Department of Surgery, Kurume University School of Medicine, 67 Asahi-machi, Kurume, Fukuoka 830-0011, Japan.

Received: 12 August 2016 Accepted: 27 October 2016

Published online: 03 November 2016

\section{References}

1. Bozzi E. So di una rara complicannza consecutive a gastroenterostomia alla V. Hacker Boll Acad Med Genova. 1914;122:3-4.

2. Narita H, Funabashi K, Yoshitomi H, Yamamori N, Iguchi T, Hori K, et al. Post operative intussusception - report of a case, and a comparison between adult and pediatric intussusceptions after laparotomy (in Japanese). Rinsyo Gaka (Clinical Surg). 1991;52:2125-31.

3. Davey WW. Retrograde intussusception following Roux-loop anastomosis in total gastrectomy. Br J Surg. 1954;42:102-3.

4. Tu BN, Kelly KA. Motility disorders after Roux-en-Y gastrojejunostomy. Obes Surg. 1994;4:219-26.

5. Kato M, Nakamura S, Hashimoto I. A case of intussusception of the jejunal afferent loop after a total gastrectomy (in Japanese). Geka Chiryo. 1965;12:495-7.

6. Freeman FJ, Bernatz PE, Brown Jr PW. Retrograde intussusception after total gastrectomy. Report of a case. Arch Surg. 1966;93:586-8.

7. Hanyu N, Suzuki H, Miho O, Nagao F. A case of jejunal intussusception after total gastrectomy (in Japanese). Nihon Syokakigeka Gakkai Zasshi (Jpn J Gastroentel Surg). 1984;17(4):791-3.

8. Hashimoto N, Fukano M, Sue K, Koyanagi N, Minagawa S. Adult retrograde intussusception after total gastrectomy (in Japanese). Geka. 1993;55(7):828-30

9. Narushima Y, Kobayashi N, Kuroda F. A case of retrograde intussusception of jejunum after total gastrectomy (in Japanese). Nihon Fukubu Kyukyuigakukaishi. 1994;14(2):363-5.
10. Goto Y, Yodonawa S, Hirano M, Fujiwara A, Ogawa I. Retrograde jejunal intussusception after total gastrectomy (in Japanese with an English abstract). Nihon Rinsyo Gaka Gakkai Zasshi (J Jpn Surg Assoc). 2000;61(6):1474-7.

11. Ozdogan M, Hamaloglu E, Ozdemir A, Ozenc A. Antegrade jejunojejunal intussusception after Roux-en-Y esophagojejunostomy as an unusual cause of postoperative intestinal obstruction: report of a case. Surg Today. 2001;31:355-7.

12. Akiyama Y, Aoki K, Nakaya T, Fujiwara H. A case of retrograde jejunal intussusception of Roux-en-Y anastomotic site after total gastrectomy (in Japanese). Geka. 2005;67(5):587-9.

13. Matsumoto T, Kawamoto K, Sano K, Ogasahara K. Retrograde intussusception of the jejunal afferent loop developed 12 years after total gastrectomy (in Japanese). Kurashiki Cyuou Byoin Nenpo. 2005;67:107-10.

14. Sato S, Shinoda M, Kawaguchi S, Abe M, Kunori T, Shinya F. Case report of 21 year postgastrectomy retrograde intussusception of the jejunum occurring distal to a Roux-en-Y anastomosis (in Japanese). Nihon Fukubu Kyukyuigakukaishi. 2006;26(3):465-7.

15. Ueno T, Takahashi M, Kanno A, Naito H. A case of chronic intussusception leading to repeat aspiration pneumonia and second intussusception (in Japanese with an English abstract). Nihon Rinsyo Gaka Gakkai Zasshi (J Jpn Surg Assoc). 2010;71(11):2864-7.

16. Matsuda S, Kanai T, Nakamura A, Kuroshima N, Ueshima T, Fukushima H, et al. A case of intussusception of jejunum after total gastrectomy that occurred for an early postoperative period (in Japanese). Hamamatsu iryo senta gakujutsushi. 2012;6(1):20-3.

17. Lee SY, Lee JC, Yang DH. Early postoperative retrograde jejunojejunal intussusception after total gastrectomy with Roux-en-Y esophagojejunostomy: a case report. J Gastric Cancer. 2013;13(4):263-5.

18. Kita K, Yabuki H, Inaba S, Ohara K, Syounaka T, Watanabe K. A case report of a relapsed retrograde intussusception at a Roux-en-Y anastomosis after total gastrectomy requiring two surgery (in Japanese with an English abstract). Nihon Rinsyo Gaka Gakkai Zasshi (J Jpn Surg Assoc). 2013;74(2):391-5.

\section{Submit your manuscript to a SpringerOpen ${ }^{\circ}$ journal and benefit from:}

- Convenient online submission

- Rigorous peer review

- Immediate publication on acceptance

- Open access: articles freely available online

- High visibility within the field

- Retaining the copyright to your article

Submit your next manuscript at $\boldsymbol{s p r i n g e r o p e n . c o m ~}$ 